\title{
Development of Effective Urinal Odour Traps for Conventional Household Urinals, Urine Diversion Dry Toilets (UDDT) and Community Urine Collection Tanks
}

\author{
Ababu T. Tiruneh ${ }^{1}$, William N. Ndlela ${ }^{1}$, Jonna Heikkilä ${ }^{2}$ \\ ${ }^{1}$ University of Swaziland, Department of Environmental Health Science, Mbabane, Swaziland \\ ${ }^{2}$ Turku University of Applied Sciences, Faculty of Technology Environment and Business, Turku, Finland
}

Email address:

atiruneh@uniswa.sz (A. T. Tiruneh), wndlela@uniswa.sz (W. N. Ndlela), jonna.heikkila@turkuamk.fi (J. Heikkilä)

\section{To cite this article:}

Ababu T. Tiruneh, William N. Ndlela, Jonna Heikkilä. Development of Effective Urinal Odour Traps for Conventional Household Urinals, Urine Diversion Dry Toilets (UDDT) and Community Urine Collection Tanks. Science Research. Vol. 4, No. 3, 2016 , pp. 79-87. doi: 10.11648/j.sr.20160403.12

Received: May 7, 2016; Accepted: May 16, 2016; Published: June 13, 2016

\begin{abstract}
Control of odour from urinal installations is an important task from considerations of health, hygiene and acceptability or use of these installations. Because of the problems associated with cost, technology and proprietary nature of many of the marketed technologies for odour control, there is a need to develop simple, easily adaptable and low cost technologies for odour traps in urinal installations. A research work was carried out for the development of simple and low cost odour control using devices that work on the principles of either buoyant force or gravity push combined with elastic band extension. The conceptual development of the odour trapping device arrangement and of the odour trapping mechanism is presented. The scientific model for determining the optimum elastic band extension for effective odour control is developed. Experiments were performed to verify the theoretical model relating force required for opening the odour trap with the optimum elastic band extension length. The experimental results were also used to determine the model parameters through regression. Different types of odour control devices were developed and installed to adapt to differing urinal installations including household level urinals, urine diversion dry toilets (UDDT) and community urine collection storage tanks. The devices, besides being simple and low cost, have more or less been found to work satisfactorily and effectively control odour from the urinal installations that they have been provided to.
\end{abstract}

Keywords: Odour Control, Ammonia, Urinals, UDDT, Urine Smell, Toilets, Urine Tanks

\section{Introduction}

Urinals are widely present in the traditional male toilets of society and as component of urine separation in urine diversion toilets (UDDT) used by both males and females [1]. A urinal is a specialized toilet for urinating only, which is used while standing up, and is designed for male users. Waterless urinals are popular in developed countries where sewer systems do not exist. They are of as much relevance to developing countries where sewer systems are the exception rather than the norm being confined to highly developed parts of cities [2]. Urinals save space and cost compared to toilets [3]. Apart from convenience, space and cost, the drive for nutrient recovery has led to increase in the use of source separated waste collection system such as urine diversion dry toilets that have separate bowl component for urine collection [4].

Water flushed urinals are traditionally common forms of urinals where water is used to flush away the urine and thereby control odour. They exist to date with varying designs that are progressively aimed at reducing the quantity of water used for flushing. However, conventional flush urinals require approximately 4 liters of water after each use or regularly based on a timer [3]. However, in some outdated flush urinal models as much as 20 liters of water may be used per flush [5]. Waterless urinals are favored over the traditional system of water flushed urinals due to the high water demand and the associated energy demand of the flushed urinals. Urine diversion dry toilets are one example where the urine diversion forms waterless urinal or separations that use low volume water for flushing residual 
urine and as such save water used for flushing toilet [2].

Odour control is cited as one issue that needs to be addresses in the provision of waterless urinals [6]. One source of odour from urine is the ammonia present after urine is stored for a short period of time. The urea present in urine is hydrolysed by urease enzymes during storage to ammonia/ammonium and this process is accompanied by an increase the $\mathrm{pH}$ value [2]. Even though odour problem is pronounced problem with waterless urinals, some studies suggested that even with flush urinals the problem of odour is not entirely eliminated where the level of ammonia in the urinal environment was essentially the same between flushed urinals and those that were not flushed [7].

The level of sophistication of urinal traps varies considerably. There are odour traps that have electromagnetic sensors which senses the users who are approaching the urinal and thereby trigger the odour seal float to open and allow urine to flow out [6]. On the other end of the spectrum, simple floatable seals such as table tennis balls or light bulbs or plastic balls placed on funnel fitted onto urine storage tanks are provided. An example of simple odour trap is the Eco Lilly developed in Ethiopia that uses simple containers fitted with funnel and light bulb as floating odour lock to reduce smells [8]. Another example is the IIT Zerdor trap which comes as a tube perforated at the top to allow urine to pass through and inside which a low density polyethylene ball sits and forms a trap when urine is not passing but floats up and allows urine during use [15].

Wide varieties of other odour trapping mechanisms have been developed and are in widespread use around the world. One example is the use of floating oil (with specific gravity less than that of water) below the urinal which can also be scented to provide a perfumed odour trap [6]. The sealant fluid may require replacement and care must be taken to exclude sealant fluids that are not biodegradable or that are toxic. Biodegradable liquid has an advantage of being degraded biologically once the sealant is flushed out of the pipe system [9]. Vegetable oil may be cheap for such purpose and widely available but may not last long as it solidifies with time [2].

A seal consisting of rubber hose that is rounded at the top and cut into two to form flat seal at the bottom are also used as odour trap $[2,6,10]$. The device is simple. No chemical, electricity or water is required to regularly operate the odour trap [11]. Such seals are, however, subject to clogging and need periodic maintenance [6]. One cause of clogging is the increased $\mathrm{pH}$ value of urine which results in precipitation of struvite $\left(\mathrm{MgNH}_{4} \mathrm{PO}_{4}\right)$ and calcium phosphate $\left(\mathrm{Ca}_{10}\right.$ $\left.\left(\mathrm{PO}_{4}\right)_{6}(\mathrm{OH})_{2}\right)$ crystals [2]. Periodic flushing with water to flush out the accumulated stones on the rubber is essential and the rubber may have to be replaced after some period of use [3]. Generally waterless urinal odour seals require periodic check and maintenance and possibly replacement after an extended period of use depending on the types and robustness of the systems provided [5].

A silicon curtain seal with Eco smell stop works in the same way as the rubber tube seal but has low maintenance requirements because of the self-cleansing properties of the inner surface of the silicon seal [2]. However, the manufacturing is relatively high technology with liquid silicon injected into mold at high temperature and with accurate quality control of the sealing properties. Such production may not be easily available in developing countries [3].

Other methods of odour trap include: Extending the urine pipe down to the bottom of the urine collecting tank thus forming liquid seal, spreading oil on the surface of the collecting tank, and, using a cutoff condom on the urine outlet pipe [2]. However, condoms were observed to stick together after some period of use [12]. Another form of odour trap, consisting of biological blocks exists. The blocks are placed on the urinal pan or on a dome housed inside the urinal and contain microbial spores and surfactants. The spores become active and degrade the urine and prevent blockages. They also generate an environment hostile to odour causing bacteria [13].

Ventilating the urine storage tank using vertical pipe (where reuse of nutrients is not the objective) is used in some cases. The familiar $U$ trap similar to water seal where the urine itself acts as a seal between the urinal and the urine storage tanks is also used in some applications although this may form further site for clogging [12]. Charcoal contained in a mesh bag and placed directly in the urine-diverting section of the user interface has been applied in the Philippines and shown to be an effective means of odour reduction [14].

\section{Materials and Methods}

This research work is based on the scientific premise that the principle of buoyancy and elasticity can be combined to form effective odour trap while at the same time triggering passage of urine automatically when the urinals are being used. A theoretical model describing the relationship between elastic extension of elastic bands and external forces applied was developed. Experimental were performed to determine the model parameters. The procedure for determining optimum elastic extension to provide effective odour trap while avoiding pooling up of urine is also presented. Examples of practical constructions of odour traps are also presented.

\subsection{Conceptual Development of the Odour Trapping Device}

The odour trap arrangement consists of trap forming device such as tennis ball, air-filled balloon or oil-filled balloon provided to a given urinal and to which elastic bands are extended and tied. The oil to be used in the balloon must have its specific gravity less than that of water. Such oils as paraffin can be used for the purpose. Vegetable oils will precipitate out and are, therefore, not suitable for forming floating devices. The trap forming devices are presstightened into position using the elastic band extension so that they form an effective odour trap. Upon usage of the urinal, the weight of the urine creates either an upward buoyant force or a down ward force of gravity that will lift or push down the trapping device and thereby allow urine to pass through the urinal. 
There are basically two types of the odour trap arrangement and shown in Figure 1 and in Figure 2. In the first arrangement shown in Figure 1, the odour trap consisting of either air-filled balloon or oil-filled balloon is placed at the central hole of the urinal and an elastic band is tied to the odour trap on the top side and is stretched downward so that it is also tied to the urinal at the bottom (refer to Figure 1 (a). This arrangement will form an effective odour trap whereby the device (air- or oil-filled balloon) is press-tightened against the top of the urinal hole and prevents odour from passing out through the urinal.

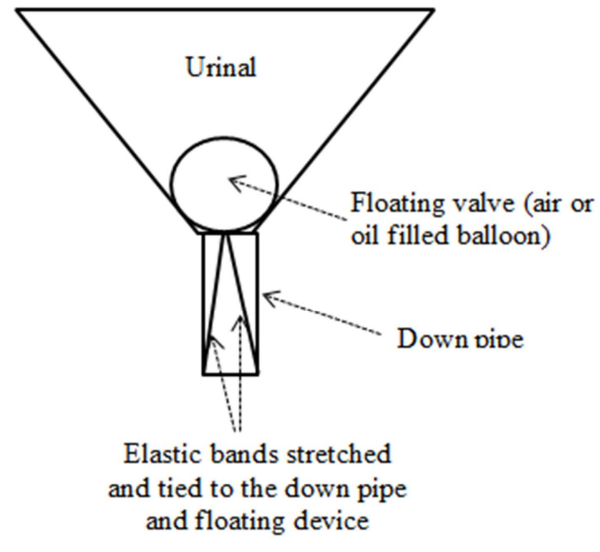

(a) Closed position

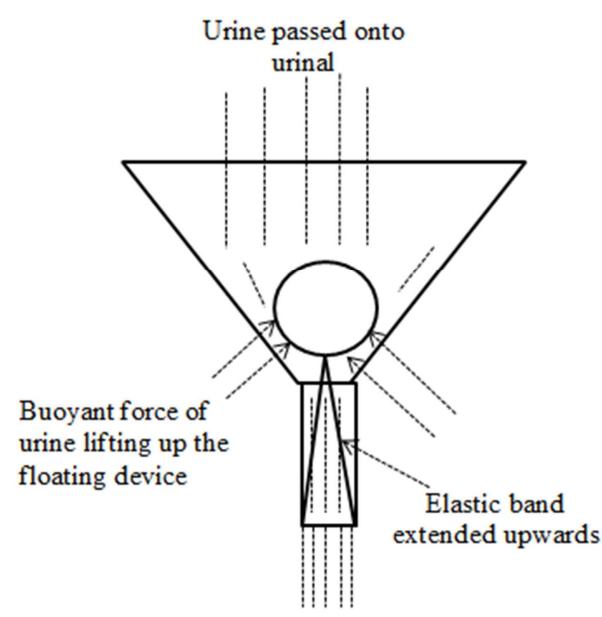

Urine passing through urinal

(b) Open position

Figure 1. Setup of odour trapping with top seal using air filled or oil filled balloon. (a) Closed position before or after passage of urine. (b) Open position during passage of urine.

Upon usage of the urinal, the weight of the urine creates a buoyant force on the balloon and if the volume of urine is adequate, it will counter-balance the elastic force holding the balloon in the tight closed position and will lift the balloon upward. This action creates an opening between the balloon and the urinal hole which will then allow urine to pass through. The balloon will eventually be pulled back to its tightened position by the elastic band attached to it once the urine passes out completely through the urinal holes.

An alternative setup shown in Figure 2 is the provision of the odour trapping device in the form of either a table tennis ball or air-filled balloon at the bottom of the urinal or down pipe. The trapping device is tied to an elastic band that is stretched upward and is tied at the top position to the urinal. The stretched elastic band exerts an upward vertical force on the trapping device and holds it in tight position. Upon usage of the urinal, the weight of the urine passing through the down pipe creates a vertical downward force that counteracts the upward elastic force in the elastic band and that holds the trap forming device tightened in upward position.

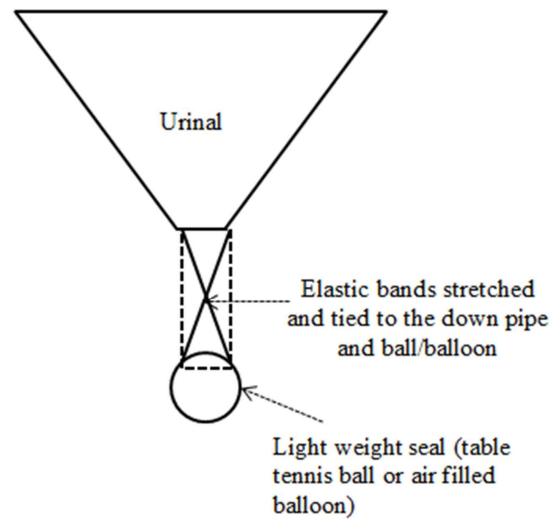

(a) Closed position Urine passed onto

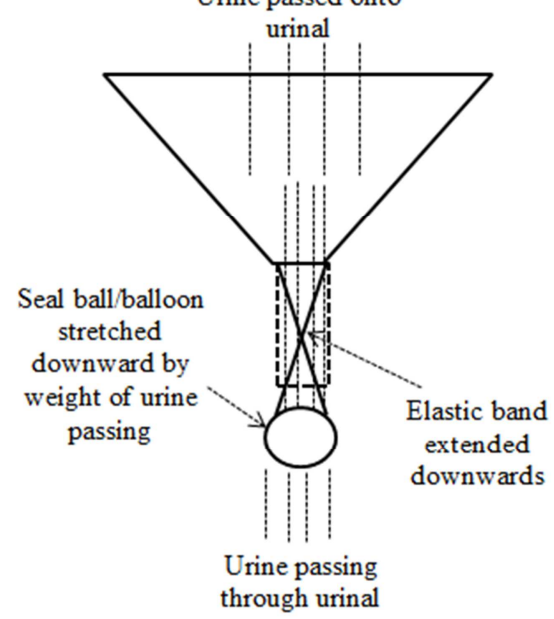

(b) Open position

Figure 2. Setup of odour trapping with bottom seal using table tennis ball or air filled balloon. (a) Closed position before or after passage of urine. (b) Open position during passage of urine.

Once the forces balance, further opening is created by more urine coming to the down pipe and the urine passes through the hole. Once the urine passes through, the odour trapping device is pulled back to its tightened closed position by the elastic band. The use of oil-filled balloon is not recommended for the downward arrangement as the weight of oil will create a downward force that stretches the elastic band too long and makes it difficult to form a tight odour trap.

An optimum extension of the elastic band should be chosen for both arrangements so that the odour trapping 
device forms an appropriate seal while at the same time being easily lifted or pulled down with small amount of urine without creating pooling up of urine.

\subsection{Development of Force-Extension Equation for Elastic Band}

The application of an external force to an elastic band as shown in Figure 3 results in proportional extension in length as well as reduction in the cross sectional area of the elastic band. The reduction in cross sectional area implies that it will successively become easier to extend the elastic band as the elastic band gets thinner until the elastic limit is reached and the elastic band becomes stiffer. As will be shown with the experimental result that follows, the extension-force graph follows an S-shaped graph.

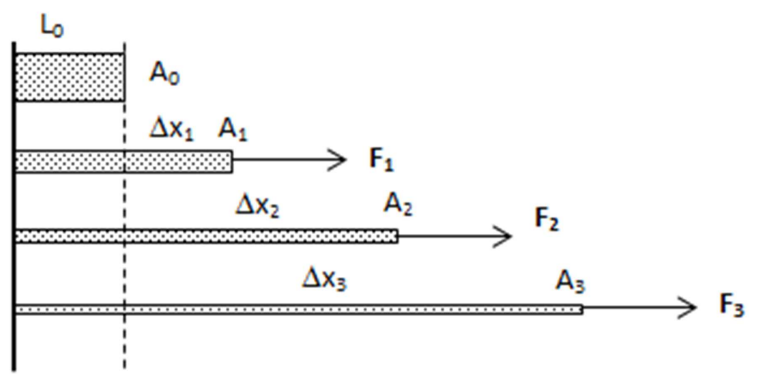

Figure 3. Extension of elastic band under the application of force with progressive reduction in cross sectional area of the elastic band.

The stressed developed in the elastic band as a result of the extension under the application of external force can be formulated as:

$$
\sigma=E \epsilon=E \frac{\Delta x}{L_{0}}
$$

Where $\sigma$ is the stress developed in $\mathrm{N} / \mathrm{mm}^{2}, \mathrm{E}$ is the modulus of elasticity of the elastic band in $\mathrm{N} / \mathrm{mm}^{2}, \varepsilon$ is the strain, $\Delta \mathrm{x}$ is the extension of the elastic band and $\mathrm{L}_{0}$ is the original length of the elastic band.

In terms of the external force $F$ and cross sectional area $A_{x}$ of the elastic band Equation (1) can also be expressed as:

$$
F=\sigma A_{x}=E \frac{\Delta x}{L_{0}} A_{x}
$$

The progressive thinning out of the elastic band as it is extended further can approximately be related to the extension length $\Delta \mathrm{x}$ as follows:

$$
A_{x} \propto \frac{1}{L_{0}+\Delta x} \Rightarrow A_{x}\left(L_{0}+\Delta x\right)=A_{0} L_{0}=\text { constant volume }
$$

Where $A_{x}$ is the cross sectional area of the elastic band, $L_{0}$ and $\mathrm{A}_{0}$ are the original length and original cross sectional area of the elastic band.

Equation (2) can now be written as:

$$
F=E \frac{\Delta x}{L_{0}} A_{x}=E \frac{\Delta x}{L_{0}}\left(\frac{A_{0} L_{0}}{L_{0}+\Delta x}\right)=E A_{0}\left(\frac{\Delta x}{L_{0}+\Delta x}\right)
$$

Equation (3) can be written in linear form as follows:

$$
\frac{1}{F}=\frac{1}{E A_{0}}\left(\frac{L_{0}+\Delta x}{\Delta x}\right)
$$

or

$$
\frac{1}{F}=\frac{L_{0}}{E A_{0}}\left(\frac{1}{\Delta x}\right)+\frac{1}{E A_{0}}=a+b\left(\frac{1}{\Delta x}\right)
$$

Where the regression constants a and $b$ determined from experimental data, are given by:

$$
a=\frac{1}{E A_{0}} ; b=\frac{L_{0}}{E A_{0}}
$$

Equation (4) above is a linear form of the equation that relates the force applied to the extension of the spring. This equation will be used to determine the amount of elastic band extension required in order to ensure odour tightness while at the same time allowing an extension opening in response to a given minimum urine volume causing the opening downward or buoyancy of the float valve upward. The constants of Equation (4) can be determined through experimental procedure which is given below under the results section.

Although the modulus of elasticity (E) is assumed constant, it will be shown later the modulus of elasticity decreases in response to decrease in the cross sectional area of the elastic band as the band is stretched further. Adjustment for change in modulus of elasticity will be made when calculating the extension length required to create a given length of opening of the odour trapping device with a maximum allowable volume of urine passing through.

\subsection{Force Required for Opening the Odour Trapping Device by a Given Gap}

The force required to open the odour trapping device can be determined based on the free body diagram of the trapping device shown in Figure 4 and Figure 5. As explained earlier, depending on the odour trap arrangement, the opening is triggered either by the upward buoyant force of the urine exerted on the floatation device forcing it to lift up or by the downward weight of urine passing through the urinal forcing the odour trapping device to push open downward.

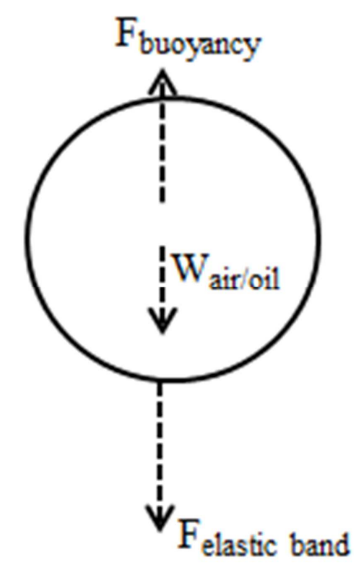

Figure 4. Free body diagram of air/oil filled balloon at the position of maximum opening for top sealed odour traps. 
Referring to the free body diagram of the air or oil-filled balloon in Figure 4, equilibrium is reached when the balloon is lifted to the maximum at which point the sum of the forces acting on the balloon must equate to zero.

$$
F_{\text {buoyancy }}-W_{\text {air(oil) }}-F_{\text {elastic band }}=0
$$

The force required to fully open the balloon is, therefore given by:

$$
F_{\text {buoyancy }}=W_{\text {air (oil) }}+F_{\text {elastic band }}
$$

This force is provided by the weight of urine initially pulling up in the urinal either in the form of buoyant force as shown above for top-sealed odour traps or in the form of downward gravity push as will be shown below for bottomsealed odour traps.

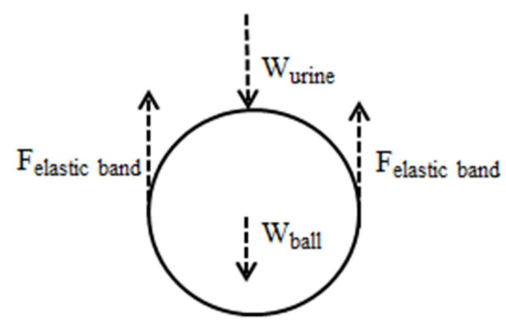

Figure 5. Free body diagram of air/oil filled balloon at the position of maximum opening for bottom sealed odour traps.

For the bottom sealed odour traps shown in the free body diagram of Figure 5, the weight exerted by urine plus the weight of the ball or air-filled balloon will force the ball to open downward and cause the elastic band to extend to a desired opening gap. At the position of maximum opening position of the ball, the three forces will be in equilibrium. Referring to the free body diagram of Figure 5 again, the weight of urine at the maximum downward position of the ball in open state and at equilibrium is calculated from:

$$
\begin{gathered}
W_{\text {urine }}+W_{\text {ball }}-F_{\text {elastic band }}=0 \\
W_{\text {urine }}=F_{\text {elastic band }}-W_{\text {ball }}
\end{gathered}
$$

In this case, the weight of the odour trapping device acts to help reduce the volume of urine required. However, the weight of both the tennis ball and air balloon are small and do not exert appreciable influence on the calculation of the volume of urine required. This is not the case for oil filled balloons in top-sealed odour traps. The weight of oil inside the balloon is significant enough to be added to the volume of urine required to cause buoyancy.

\subsection{Determination of the Optimum Elastic Band Extension}

The determination of optimum elastic band extension is required so that the odour trapping device is not too tight requiring large volume of urine to lift or push the odour trapping device and leading to pooling up of the urine and residual urine left on the urinal beside urine draining slow and poorly. On the other hand, the elastic band shall not be too loose so that the odour trapping device does not form effective odour tight trap. Two alternative procedures can be used to determine the optimum elastic band extension. i.e., graphical method and using formula. The procedures for both methods are described below in detail.

Method 1: Graphical method

The procedure for determining the optimum extension of the elastic band using graphical method is as follows:

1. Assume initial length of elastic band needed for forming tight odour trap, $\mathrm{L}_{0}$, cross sectional area of the elastic band $\mathrm{A}_{0}$.

2. Assume a maximum acceptable urine volume of urine, $\mathrm{V}_{\max }$, that is allowed to pool up on the urinal and triggers the opening of the odour trap

3. To start the iteration, assume a starting value of extension of the elastic band, $\Delta x$, that forms an effective odor trap so that the total extended length of the elastic band in closed position is given by:

$$
L_{\text {closed }}=L_{0}+\Delta x
$$

4. From the regression equation relating external force applied and elastic band extension given by Equation (4), determine the force required to extend the elastic band and form effective odour trap

$$
\frac{1}{F_{\text {closed }}}=a+b\left(\frac{1}{\Delta x}\right)
$$

5. Assume minimum suitable opening necessary to be created by buoyancy or downward motion of the odour trapping device resulting in the extension of the elastic band. Let this value be $\mathrm{e}_{\mathrm{min}}$.

6. From the regression equation relating external force applied and elastic band extension determine the force required to extend the elastic band and open the odour trap fully.

$$
\frac{1}{F_{\text {open }}}=a+b\left(\frac{1}{\Delta x+e_{\text {min }}}\right)
$$

7. Determine the mass of urine required on the basis that the force is provided either through buoyancy on the floatable trapping device (air- or oil-filled balloon) or through the downward force exerted by the urine on the odour tight device (tennis ball or air balloon).

$$
\begin{aligned}
& M_{\text {urine }}=\frac{F_{\text {open }}+W_{\text {air (oil)baloon }}}{g} \ldots \ldots \ldots \text { for top sealed traps } \\
& M_{\text {urine }}=\frac{F_{\text {open }}-W_{\text {ball }}}{g} \ldots \ldots \text { for bottom sealed traps }
\end{aligned}
$$

Where $g$ is the acceleration due to gravity.

8. For a given density of urine, $\rho_{\text {urine, determine the }}$ volume of urine required to form the critical mass require, $\mathrm{M}_{\text {urine }}$ to open the odour trap:

$$
V_{\text {urine }}=\frac{M_{\text {urine }}}{\rho_{\text {urine }}}
$$


9. Repeat the steps 3-8 above thereby forming paired data in terms of elastic extension and the associated volume of urine required, i.e., $\left(\Delta x, V_{\text {urine }}\right)$.

10. Plot a graph of elastic extension $(\Delta x)$ as the $x$-axis and the corresponding volume of urine required $\left(\mathrm{V}_{\text {urine }}\right)$ as the $\mathrm{y}$-axis. Locate the optimum elastic band extension $\Delta \mathrm{x}_{\mathrm{opt}}$. corresponding to the maximum initial volume of urine $\left(\mathrm{V}_{\max }\right)$ that is allowed to accumulate on the urinal to trigger opening of the trapping device either by floatation (in the case of top seal trapping devices) or by downward pushing of the trapping device (in the case of bottom sealed traps)

\section{Method 2: Using formula}

Denoting the optimum elastic band extension force required corresponding to the optimum extension length $\Delta \mathrm{x}_{\mathrm{opt}}$ as $\mathrm{F}_{\mathrm{opt}}$ and using the regression equation of equation (4) relating $\mathrm{F}$ and $\Delta \mathrm{x}$ the following equation can be written

$$
\frac{1}{F_{\text {optimum }}}=a+b\left(\frac{1}{\Delta x_{\text {optimum }}+e_{\text {min }}}\right)
$$

The optimum extension force can be written in terms of the maximum volume of urine allowed to initially pool up, $\mathrm{V}_{\max }$ and the density of urine, $\rho_{\mathrm{u}}$, i.e.,

$$
F_{\text {optimum }}=V_{\text {max }} \rho_{u} g \mp W_{\text {ball(balloon) }}
$$

The minus sign in Equation (6) is for top-sealed traps and the plus sign for bottom sealed traps.

Substituting this expression for $\mathrm{F}_{\mathrm{opt}}$ in Equation (5);

$$
\frac{1}{V_{\max } \rho_{u} g \mp W_{\text {ball(balloon) }}}=a+b\left(\frac{1}{\Delta x_{\text {opt }}+e_{\text {min }}}\right)
$$

Solving for $\Delta \mathrm{x}_{\mathrm{opt}}$ and rearranging gives;

$$
\Delta x_{o p t}=\frac{b\left(V_{\max } \rho_{u} g \mp W_{\text {ball(balloon })}\right)}{1-a\left(V_{\max } \rho_{u} g \mp W_{\text {ball(balloon })}\right)}-e_{\min }
$$

\subsection{Experimental Setup for the Determination of Elastic Band Force-Extension Relationship}

An experiment was setup for the purpose of determining the elastic band's force vs. extension relationship based on the theoretical foundation developed and presented earlier in this section. A given elastic band that has commonly been used for the construction of the odour trap and that has a cross-sectional dimension of $1 \mathrm{~mm}$ by $4 \mathrm{~mm}$ and length oh $11.2 \mathrm{~cm}$ is tied to a 1.5 liter empty bottle and the original length of the elastic band measured as shown in Figure 6:(a). Following this, a measured volume of water is added to the bottle and the bottle is hanged again and the resulting extension of the elastic band as result of the combined weight of the empty bottle and the water is measured. The procedure of adding measured volume of water and measuring the resultant extension length of the elastic band is repeated several times so that adequate data for measuring the trend and regression constants are generated.

The data generated are modeled in accordance with the equations developed and outlined in this section above. A graph of the force vs. extension is generated. The linear form of the force-extension equation is used to plot the trend as well as carry out linear regression analysis for determining the model constants which will be used for design of the odour trap as explained in this section above.

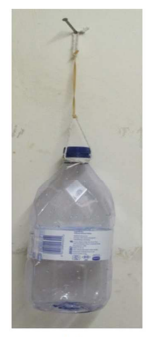

(a)

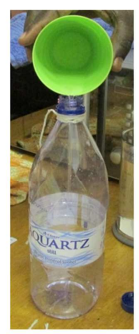

(b)

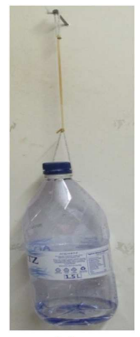

(c)

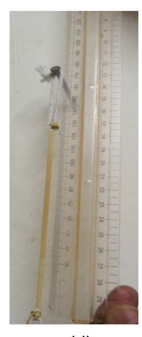

(d)
Figure 6. Elastic band force-extension experimental setup. (a) Elastic band tied to empty bottle and hanged while original band length is noted. (b) Measured volume of water added to bottled. (c) Bottle is hanged again with resulting extension of elastic band. (d) The extended length is measured with ruler or measuring tape.

\section{Results and Discussion}

The plot of experimental data used for determining the force-extension relationship is shown in Figure 7 where by the volume of water added in each step of the experiment is converted to the equivalent weight in Newton and plotted on the x-axis. The resulting extension of the elastic band in $\mathrm{cm}$ in response to the resultant weight of water added in the bottle is plotted on the y-axis.

The data plot of Figure 7 display an S-shaped curve. Initially the increase in length of the elastic band is linear. Later as more and more force is applied the elastic band gets thinner and the extension grows exponentially. Finally when the elastic limit is reached as greater force is applied, the extension curve evens out. In terms of the stiffness of the elastic band, the graphs shows a constant stiffness initially followed by a decrease in stiffness values and finally an increase in stiffness as the elastic limit is reached.

Figure 8 shows a plot of the regression analysis results based on the linear form of the force-extension relationship of the elastic band developed and presented in Equation (4). The data plot as straight line with coefficient of determination $\left(\mathrm{R}^{2}\right)=0.99$. The model parameters $\mathrm{a}$ and $\mathrm{b}$ are also worked out and indicated in the plot.

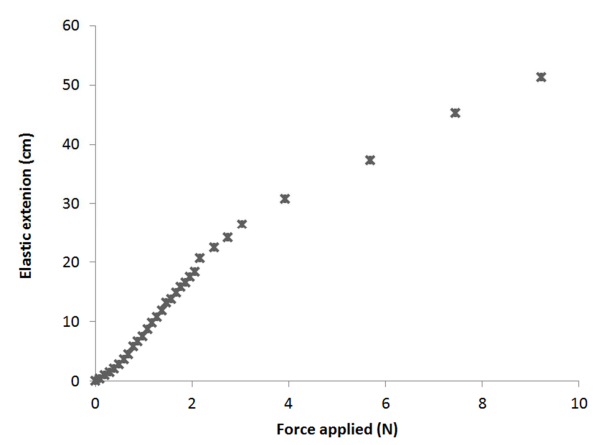

Figure 7. Plot of the force applied in $(N)$ and the resulting extension of the elastic band showing an S-shaped curve. 


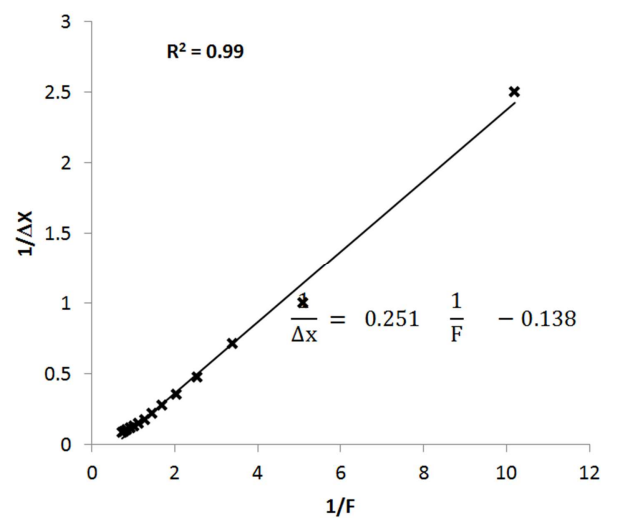

Figure 8. Linear form of the force-extension equation for the elastic extension range $(0-12 \mathrm{~cm})$.

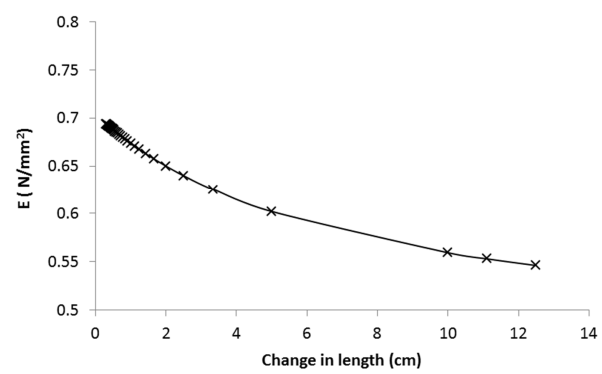

Figure 9. Variation of the Modulus of elasticity (E) of the elastic band with extended length.

The decrease in stiffness of the elastic band as it is extended further can be seen from Figure 9 which shows the calculated plot of the modulus of elasticity and its variation with change in length of the elastic band as it gets thinner through extension. However, despite the decrease in the stiffness, it will be shown further that when the elastic band is extended further and press tightens the closing device, more volume of urine is required to create opening through further extension of the elastic band. The reason for this is the greater amount of strain that is present in an extended/tight elastic band.

Figure 10 shows the amount of urine that is required to create an opening of $0.5 \mathrm{~cm}$ through further extension of the elastic band. The opening of the device is created by the buoyant force of the urine exerted on the floatable device such as elastic air-filled balloon or balloon filled with paraffin oil. Alternatively, the opening can be created by the downward weight of the urine exerting force on the closing device which can be a tennis ball or air-filled balloon. In both cases, the volume of urine required is the same since because of Archimedes principle the force exerted on floatable air-filled balloon or oil-filled balloon is equivalent to the weight of the displacing liquid which is the urine poured on the urinal.

Examination of Figure 10 shows that an optimal extension of the elastic band for a given original length should be chosen so that the odour trapping device (tennis ball or floatable air/oil filled balloon) works properly. If the extension is very small, the odour trap will not form an effective odour seal although the amount of urine required to lift the floatable device is conveniently small. On the other hand, if the elastic band extension is too long, creating a very tight closing of the floatable device, the amount of urine required will be too large causing pooling up of urine on the urinal which is aesthetically undesirable as well as leaving traces of smelling urine on the urinal since not all of the urine eventually drains through.

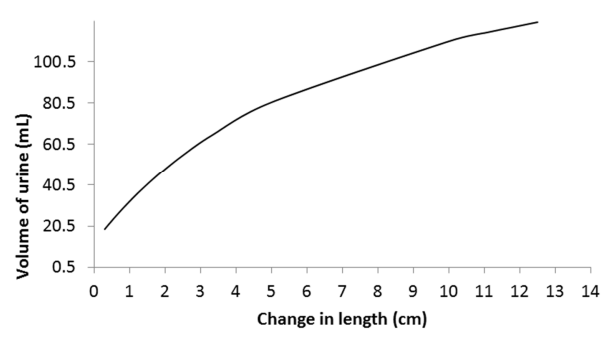

Figure 10. Volume of urine required to create a $5 \mathrm{~mm}$ opening through extension of the elastic band.

\section{Examples of constructions of the different odour trapping} devices

Figure 11-13 show photographs of the construction of the different odour trapping devices adapted to different urinal environments. The examples include odour traps for topsealed as well as bottom-sealed positions, odour trap incorporating a combination of both top and bottom seals, odour traps incorporating air-filled balloons, odour traps incorporating table tennis balls and odour traps using balloons filled with paraffin oils.
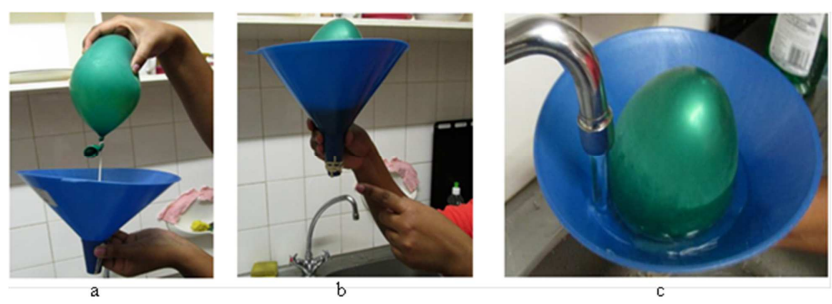

Figure 11. Top sealed odour trap on urinal funnel. (a) Elastic band extended to its limit showing mechanism of opening. (b) Elastic band tied to down pipe of urinal. (c) Balloon opening under buoyancy of water where too tight elastic band causes the opening gap to be small.

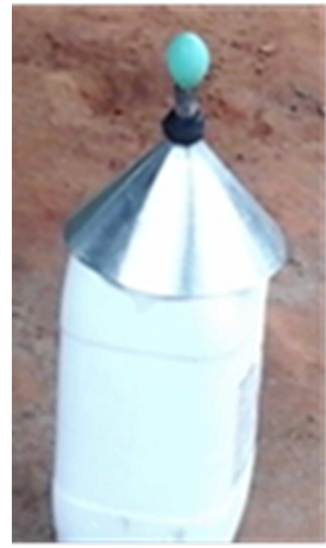

a

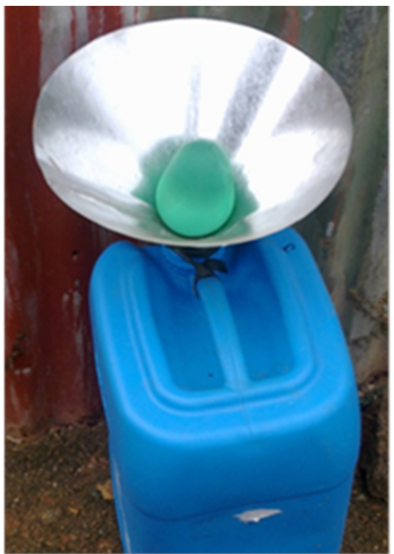

b
Figure 12. Odour traps fitted to urine storage jerry cans. (a) Bottom seal odour trap with air-filled balloon. (b) Top seal odour trap with air-filled balloon. 


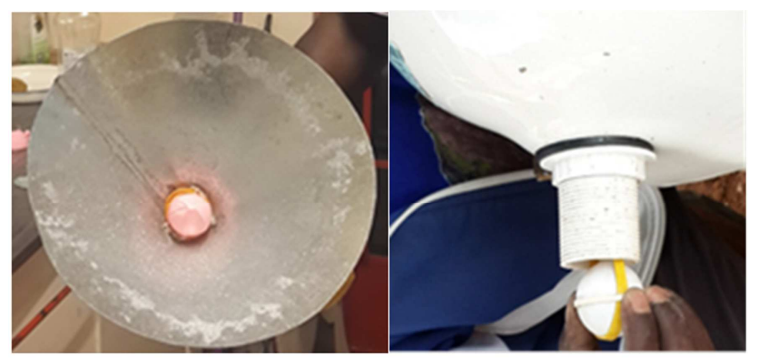

(a)

(b)

Figure 13. (a) Odour trap formed by paraffin oil (specific gravity $=0.8$ ). (b) Bottom sealed odour trap using tennis ball and elastic band fitted to male urinal of a toilet.

\section{Conclusion}

Odours generated from urine present in toilets are challenging problems which affect the aesthetic and hygienic environment as well as the use and acceptability of toilets. Solutions for preventing odours coming from urinals are varied ranging from simple devices to more complicated ones some of which are difficult to build or adapt, possibly expensive or even protected by patent rights. It is necessary, therefore, to develop simple, low cost and adaptable odour trap solutions that can be flexibly provided to urinals operating under varying toilet environments.

A conceptual development of self-operating or automatic odour trap devices that work on the principles of buoyancy or gravity push created by urine combined with forces developed in elastic bands has been made. Such a concept of odour trap is used to produce odour tightness while allowing opening of the urinal hole through elastic band extension caused by the forces of the urine passing through the urinal. Two alternative setups are presented based on the position of the odour trap, i.e., top sealed odour traps or bottom sealed odour traps. A set of simple materials that can be used to construct the odour tapping devices are suggested. These include air-filled balloons, oil-filled balloons using oils that have specific gravity less than that of water and table tennis balls.

The formula for determining the elastic force vs. extension relationship of elastic bands has been developed and was shown that an S-shaped curve defines the relation which implies a set of constant, linearly increasing and later on decreasing stiffness or modulus of elasticity of the elastic band under the influence of progressively increasing external applied force. Such a variation is due to a combination two factors. These are: Reduction of the cross sectional area of the elastic band as more force is applied and due to the fact that as the elastic limit is reached with application of excessive force, the stiffness or modulus of elasticity of the elastic band increases.

Experiments were performed in order to determine the model parameters of the elastic band extension which were used in the procedure for the determination the optimum elastic band extension for ensuring effective odour trapping. The optimum extension of the elastic band during closing of the trap is necessary to form effective odour tightness while at the same time enabling easy opening of the trapping device during use through the buoyant force generated by the urine that pools up on the urinal or the downward force created by the urine passing through the downpipe. Too tight an elastic band extension, while forming effective odour trap, will make it difficult to open the trapping device leading to pooling up of urine. Too loose an elastic band tightening fails to form effective odour trap although opening the trapping device is relatively easier.

Examples of different odour traps that were constructed through this research have been illustrated ranging from, top sealed or bottom sealed odour traps that were be provided to urine storage tanks of urine diversion dry toilets and household storage tank based urinals, to bottom seals provided to conventional male urinals that use table tennis balls combined with elastic band.to form the odour trap. It is anticipated that such simple and low cost odour trap solutions will be especially attractive in non-conventional toilet installations where expensive odour trap devices may be hard to acquire. The odour traps developed through this research and presented herewith can be easily constructed from locally available materials with appropriate training given to practitioners. It is also anticipated that the replacement of components of the odour trap such as balloons, elastic bands or table tennis balls is a low cost undertaking and can be afforded by many communities.

\section{Acknowledgment}

This research study was supported by the government of Finland as part of the Mbabane Dry Sanitation and Waste Management Project (MDSWMP) research activity. The researchers would like to thank the financial assistance provided for carrying out the research work.

\section{References}

[1] Martin, J. and Heaney J. (2008) Water use by urinals. Conserve Florida Water Clearinghouse. Dept. of Environmental Engineering Sciences. University of Florida.

[2] Münch, E and Winker, M. (2009) Technology review of urine diversion components. Deutsche Gesellschaft für Technische Zusammenarbeit GmbH (GTZ).

[3] Dahm, P and Munch, E. (2009) Waterless urinals: a proposal to save water and recover urine nutrients in Africa. 34th WEDC International Conference, Addis Ababa, Ethiopia.

[4] Chiarawatchai, N., Florian, K., Werner, C., Bracken, P. (2005) Technical data sheets for ecosan components ecosan sector project GTZ-ecosan team, Deutsche Gesellschaft für Technische Zusammenarbeit (GTZ) GmbH.

[5] Tilley, E.; Ulrich, L.; Luethi, C.; Reymond, P.; Zurbruegg, C. (2014): Compendium of Sanitation Systems and Technologies. 2nd Revised Edition. Duebendorf, Switzerland: Swiss Federal Institute of Aquatic Science and Technology (Eawag).

[6] Demiriz, M. (2005) Application of Dry Urinals. Gelsenkirchen University of Applied Sciences, 45877 Gelsenkirchen / Germany. 
[7] Fischer, D. R. (2007) Waterless Urinals; Research and Myths. CFM, LEED-AP.

[8] NWP (2006) Smart sanitation solutions: Examples of innovative, low-cost technologies for toilets, collection, transportation, treatment and use of sanitation products. $4^{\text {th }}$ World water forum, Mexico.

[9] Oldenburg et al. (2009) Urban urine diversion and grey water treatment system. Case study of sustainable sanitation projects, Linz, Austria.

[10] Winker, M.; Groenwall, P. N. (2010) Waterless urinal sheds in the inner city, Hamburg, Germany. Eschborn: Sustainable Sanitation Alliance (SuSanA).

[11] Schuetze, T., Fandino, V. S. (2014) Terra Preta Sanitation: A key component for sustainability in the urban environment. Sustainability, 6, 7725-7750.
[12] Rieck, C., Münch, E., Hoffmann, H. (2012) Technology Review of Urine-diverting dry toilets (UDDTs): Overview of design, operation, management and costs. Deutsche Gesellschaft für Internationale Zusammenarbeit (GIZ) GmbH, Bonn, Germany.

[13] Chariar, V. M., Sakthivel, S. R. (2013) Waterless Urinals: A Resource Book. UNICEF.

[14] Gensch, R., Miso, A., Itchon, G., Sayre, E. (2010) Low cost sustainable sanitation solutions for Mindanao and the Philippines - A practical construction field guide. Sustainable Sanitation Center, Xavier University, Philippines.

[15] Chariar, V. (2009) IIT Zerodor - Waterless Urinal Odour Prevention Trap. Centre for Rural Development and Technology Indian Institute of Technology Delhi, Hauz Khas, New Delhi. 